\title{
Aspectos emocionais decorrentes do processo de abortamento: Uma revisão
}

\section{integrativa}

\author{
Emotional aspects arising from the abortion process: An integrative review \\ Aspectos emocionales derivados del proceso de aborto: Una revisión integradora
}

Recebido: 01/05/2021 | Revisado: 10/05/2021 | Aceito: 15/05/2021 | Publicado: 31/05/2021

Maria Eduarda Leal de Carvalho Santos

ORCID: https://orcid.org/0000-0003-3400-0570 Centro Universitário de Ciências e Tecnologia do Maranhão, Brasil E-mail: eduardalealcs@gmail.com

Kaio Germano Sousa da Silva

ORCID: https://orcid.org/0000-0003-4236-6230 Centro Universitário de Ciências e Tecnologia do Maranhão, Brasil E-mail: kaiogsds@hotmail.com

Chrisllayne Oliveira da Silva

ORCID: https://orcid.org/0000-0002-0844-0268 Centro Universitário de Ciências e Tecnologia do Maranhão, Brasil E-mail: chris-layne10@hotmail.com

Eduardo Brito da Silva

ORCID: https://orcid.org/0000-0002-8571-7806 Centro Universitário de Ciências e Tecnologia do Maranhão, Brasil E-mail: eduzinhobds@gmail.com Joyce de Sousa Leal

ORCID: https://orcid.org/0000-0003-2972-016X Centro Universitário de Ciências e Tecnologia do Maranhão, Brasil E-mail: joyce-leal-12@hotmail.com

Cristina Soares Oliveira

ORCID: https://orcid.org/0000-0002-4917-6811 Centro Universitário de Ciências e Tecnologia do Maranhão, Brasil E-mail: csoaresoliveira27@gmail.com

Rondinelle dos Santos Chaves

ORCID: https://orcid.org/0000-0003-4941-8005 Instituto Sírio Libanês de Ensino e Pesquisa, Brasil E-mail: rondinelledsch@hotmail.com

Luana Pereira Ibiapina Coêlho

ORCID: https://orcid.org/0000-0002-2054-959X

Faculdade de Venda Nova imigrante, Brasil E-mail: luana_ibiapina@ hotmail.com

Pedro Henrique Medeiros de Andrade

ORCID: https://orcid.org/0000-0003-1819-9540

Centro Universitário de Ciências e Tecnologia do Maranhão, Brasil E-mail: pedro.medeiroscx@gmail.com

Karolayne Brito Silva

ORCID: https://orcid.org/0000-0002-3679-9091 Centro Universitário de Ciências e Tecnologia do Maranhão, Brasil

E-mail: karolaynebrito2018@outlook.com

Larissa Fernanda Pereira da Silva Araújo

ORCID: https://orcid.org/0000-0003-2200-6334

Centro Universitário de Ciências e Tecnologia do Maranhão, Brasil E-mail: larifer_18@outlook.com

Antonia Alice Dias de Sena

ORCID: https://orcid.org/0000-0001-5198-2874

Centro Universitário de Ciências e Tecnologia do Maranhão, Brasil E-mail: sennaalicemaria@gmail.com

Livia Graciela Machado de Oliveira Bezerra

ORCID: https://orcid.org/0000-0002-5680-0985

Universidade Estadual do Maranhão, Brasil E-mail: liviamachado535@gmail.com

Mayra Raisa Sena Sousa

ORCID: https://orcid.org/0000-0001-5519-1754

Centro Universitário de Ciências e Tecnologia do Maranhão, Brasil E-mail: maraisasenna953@gmail.com 


\author{
Audicelia Sousa dos Santos \\ ORCID: https://orcid.org/0000-0002-9803-5433 \\ Centro Universitário de Ciências e Tecnologia do Maranhão, Brasil \\ E-mail: audicelias10@gmail.com \\ Washington Walber Macedo dos Santos \\ ORCID: https://orcid.org/0000-0003-4577-1143 \\ Centro Universitário de Ciências e Tecnologia do Maranhão, Brasil \\ E-mail: mwashingtonwalber@gmail.com \\ Patrícia Frazão da Costa \\ ORCID: https://orcid.org/0000-0002-7437-7754 \\ Centro Universitário de Ciências e Tecnologia do Maranhão, Brasil \\ E-mail: pattyh95.frazao@gmail.com \\ Surama Almeida Oliveira \\ ORCID: https://orcid.org/0000-0002-9746-5765 \\ Centro Universitário de Ciências e Tecnologia do Maranhão, Brasil \\ E-mail: Su.a.oliveira@hotmail.com
}

\begin{abstract}
Resumo
A questão do aborto no Brasil é um dos grandes problemas de saúde pública atualmente. Esta situação afronta não somente à saúde mental e física feminina, mas também questões religiosas, culturais e sócio econômicas na qual a mulher está inserida. O estudo teve como objetivo destacar os fatores emocionais que são decorrentes do processo de abortamento. Trata-se de uma revisão integrativa da literatura, onde para tal formulou-se a questão norteadora "Quais são as alterações emocionais que podem acometer mulheres após o processo de abortamento?". Montou-se uma estratégia PICo, na qual por meio de descritores e palavras chaves consultou-se as seguintes bases de dados, BIREME (Centro Latino-Americano e do Caribe de Informação em Ciências da Saúde), SCIELO (Scientific Eletronic Library OnLine), MEDLINE (Medical Literature Analysis and Retrieval System Online) serviram como instrumento para coleta de dados. Foram incluídas apenas as publicações que responderam à questão do estudo, publicadas no período de 2014 a 2020, nos idiomas português, inglês e espanhol e testes realizados em humanos. Selecionou-se 10 estudos onde eles avaliaram a mulher desde o processo da tomada da decisão do aborto e seus motivos, até meses depois, quando o pensamento da realização do ato ainda perdura. Os dados apresentados nesta pesquisa têm o intuito de apresentar a natureza multifacetada do aborto descrito na literatura cujo impacto da perda, atinge diretamente a vida da mulher. Ele afeta sua autoestima, o modo como ela vê o próprio corpo, seu estado de espírito e uma possível futura gravidez.
\end{abstract}

Palavras-chave: Aborto; Emoções; Mulheres.

\begin{abstract}
The issue of abortion in Brazil is one of the major public health problems today. This situation affronts not only women's mental and physical health, but also religious, cultural and socio-economic issues in which women are inserted. The study aimed to highlight the emotional factors that result from the abortion process. It is an integrative literature review, where the guiding question was formulated "What are the emotional changes that can affect women after the abortion process?". A PICo strategy was set up, in which, by means of descriptors and keywords, the following databases were consulted, BIREME (Latin American and Caribbean Center for Health Sciences Information), SCIELO (Scientific Eletronic Library OnLine), MEDLINE (Medical Literature Analysis and Retrieval System Online) served as an instrument for data collection. Only publications that answered the study question, published between 2014 and 2020, in Portuguese, English and Spanish and tests performed on humans were included. 10 studies were selected where they evaluated women from the abortion decision-making process and its reasons, until months later, when the thought of performing the act still lingers. The data presented in this research are intended to present the multifaceted nature of abortion described in the literature whose impact of the loss directly affects the woman's life. It affects her self-esteem, the way she sees her body, her state of mind and a possible future pregnancy.

Keywords: Miscarriage; Emotions; Women.
\end{abstract}

\title{
Resumen
}

El tema del aborto en Brasil es uno de los principales problemas de salud pública en la actualidad. Esta situación atenta no solo a la salud mental y física de las mujeres, sino también a cuestiones religiosas, culturales y socioeconómicas en las que se insertan las mujeres. El estudio tuvo como objetivo resaltar los factores emocionales que resultan del proceso de aborto. Se trata de una revisión integradora de la literatura, donde se formuló la pregunta orientadora “¿Cuáles son los cambios emocionales que pueden afectar a las mujeres luego del proceso de aborto?". Se configuró una estrategia PICo, en la cual, mediante descriptores y palabras clave, se consultaron las siguientes bases de datos, BIREME (Centro Latinoamericano y del Caribe de Información en Ciencias de la Salud), SCIELO (Biblioteca Científica Electrónica en Línea), MEDLINE (Análisis de Literatura Médica y Retrieval System Online) sirvió como instrumento para la recopilación de datos. Solo se incluyeron publicaciones que respondieron a la pregunta del estudio, publicadas entre 2014 y 2020 , en portugués, inglés y español y pruebas realizadas en humanos. Se seleccionaron 10 estudios donde evaluaron a mujeres desde el proceso de toma de decisiones sobre el aborto y sus 
motivos, hasta meses después, cuando aún perdura la idea de realizar el acto. Los datos presentados en esta investigación están destinados a presentar la naturaleza multifacética del aborto descrito en la literatura cuyo impacto de la pérdida afecta directamente la vida de la mujer. Afecta su autoestima, la forma en que ve su cuerpo, su estado de ánimo y un posible embarazo futuro.

Palabras clave: Aborto espontáneo; Emociones; Mujeres.

\section{Introdução}

De acordo Mirabete e Fabrinni (2018), a definição de aborto é quando ocorre a interrupção da gravidez com destruição do ovo, feto ou embrião (sendo cada um destes definido por um determinado período de tempo). Segundo Oliveira e Rodrigues (2014) de 1990 a 2014 a Organização Mundial da Saúde (OMS), divulgou que o número de abortos aumentou globalmente em 5,9 milhões e que ocorrem anualmente no Brasil, cerca de 800.000 abortos, representando a quarta causa de morte materna. Considerando que o aborto no Brasil é ilegal, os casos que acontecem podem ser interligados com a desigualdade social gerando um aumento dos custos ao sistema de saúde devido as complicações na saúde da mulher (Mirabete \& Fabrinni, 2018). No país, as mulheres ainda enfrentam sérios obstáculos ao acesso a contraceptivos reversíveis e seguros na rede pública de saúde, embora seja alta a prevalência da esterilização feminina. Foi constatado que, uma das maiores causas de aborto hoje em dia, é o precário controle pré-natal (Cardoso, Vieira, \& Saraceni, 2020).

Diante deste cenário, é necessário que os profissionais de saúde estejam devidamente orientados e sensibilizados tanto para a saúde física da mulher quanto para a saúde mental ao passar pelo processo de luto (Roldán, 2016). Apesar do aborto ser um problema obstétrico comum na rotina do enfermeiro, há diversos estudos que comprovam que a mulher passa por uma fase de depressão, luto e tristeza pelo filho perdido, principalmente para as que passaram por aborto espontâneo (McCallum, Menezes, \& Reis, 2016).

Segundo Nonnenmacher et al. (2014), a visão do parceiro ainda é raramente discutida, visto o importante papel de apoio que ele pode exercer na mulher. Sua participação como apoio é definida de acordo com o tipo e a qualidade do seu relacionamento com a mulher. São poucos os artigos encontrados falando sobre o papel e a visão do aborto pela perspectiva homem e quando o citam é através da fala da mulher.

Dentro dessa perspectiva, a pesquisa se propõe a investigar a importância de um estudo mais aprofundado sobre esta matéria e da busca por soluções para este grave problema de saúde pública, partindo da justificativa da relevância da temática no quesito social, uma vez que afeta com maiores proporções as classes menos abastadas e manifesta grandes polêmicas no país, além de sua relevância para a saúde, sobretudo no tocante aos reflexos psicológicos sofridos pelas mulheres que passam pelo problema, além da relevância acadêmica, uma vez que pretende incorporar conhecimento para as pesquisas na área. Portanto, este estudo teve como objetivo por meio da literatura científica analisar os fatores emocionais que são decorrentes do processo de abortamento.

\section{Metodologia}

Trata-se de uma pesquisa bibliográfica descritiva de abordagem qualitativa feita por meio de uma revisão integrativa da literatura, que reúne e analisa dados a partir de um tema em específico.

Seguindo a metodologia de Oliveira et al. (2016), foi utilizada a estratégia PICo para a elaboração da questão norteadora da pesquisa, a qual facilitou a busca nas bases de dados com o uso de descritores e palavras chave (Quadro 1). A questão de pesquisa delimitada foi: "Quais são as alterações emocionais que podem acometer mulheres após o processo de abortamento?" Nela, o primeiro elemento da estratégia ( $\mathrm{P}$ = População) consiste na paciente que passou pelo processo de aborto; o segundo ( $\mathrm{I}=$ Interesse), as alterações emocionais; e o terceiro elemento ( $\mathrm{Co}=$ Contexto), o aborto. 
Quadro 1. Elementos da estratégia PICo (descritores, Títulos e Palavras-chaves).

\begin{tabular}{|c|c|c|c|c|c|}
\hline \multicolumn{2}{|c|}{ Elementos } & Mesh & Decs & Scielo & Palavras-chave \\
\hline $\mathbf{P}$ & "Mulheres" & "Women" & $\begin{array}{l}\text { Women" } \\
\text { "Mulheres" } \\
\text { "Mujeres" }\end{array}$ & "Women" & "Women" \\
\hline I & $\begin{array}{l}\text { "Aspectos } \\
\text { emocionais" }\end{array}$ & "Psychology" & $\begin{array}{l}\text { "Stress psychologic" } \\
\text { "Estrés Psicológico" } \\
\text { "Estresse Psicológico" }\end{array}$ & $\begin{array}{c}\text { "Stress } \\
\text { psychologic" }\end{array}$ & $\begin{array}{l}\text { "Emotional } \\
\text { aspects" }\end{array}$ \\
\hline Co & "Aborto" & $\begin{array}{c}\text { "Abortion, } \\
\text { Spontaneous" }\end{array}$ & $\begin{array}{l}\text { Abortion, Spontaneous } \\
\text { "Aborto Espontáneo" } \\
\text { "Aborto Espontâneo" }\end{array}$ & $\begin{array}{c}\text { "Abortion, } \\
\text { Spontaneous " }\end{array}$ & $\begin{array}{l}\text { Miscarriage" } \\
\text { "Abortion" }\end{array}$ \\
\hline
\end{tabular}

Fonte: Base de Dados (2020).

As bases de dados utilizadas foram: dados BIREME (Centro Latino-Americano e do Caribe de Informação em Ciências da Saúde); SCIELO (Scientific Eletronic Library OnLine); e PUBMED (National Library of Medicine) (Quadro 2).

Quadro 2. Estratégias e terminologias de busca nas bases de dados BIREME, PUBMED e SCIELO.

\begin{tabular}{|c|l|c|c|c|}
\hline Base de dados & \multicolumn{1}{|c|}{ Estratégia de Busca/terminologia } & Resultados & Filtrados & Selecionados \\
\hline $\begin{array}{c}\text { BIREME } \\
\text { (descritores } \\
\text { Decs) }\end{array}$ & $\begin{array}{l}\text { (tw:(Women)) AND (tw:(Stress psychologic)) } \\
\text { AND (tw:(Abortion, Spontaneous)) }\end{array}$ & 140 & 49 & 1 \\
\hline $\begin{array}{c}\text { PUBMED } \\
\text { (descritores } \\
\text { MESH) }\end{array}$ & $\begin{array}{l}\text { ((Women) AND (Stress psychologic)) AND } \\
\text { (Abortion Spontaneous) }\end{array}$ & 188 & 50 & 5 \\
\hline SCIELO & $\begin{array}{l}\text { (Women) AND (Abortion, Spontaneous) AND } \\
\text { (Abortion) AND (Estresse Psicológico) }\end{array}$ & 1067 & 290 & 4 \\
\hline
\end{tabular}

Fonte: Base de Dados (2020).

Quanto à amostra, os artigos foram selecionados a partir da variável de interesse, totalizando 10 artigos. A seleção foi realizada a partir da leitura criteriosa dos artigos encontrados nas bases de dados, sendo selecionada apenas a literatura que atendia aos critérios de inclusão definidos neste estudo. Foram incluídas apenas as publicações que responderam à questão do estudo, publicadas no período de 2014 a 2020, nos idiomas português, inglês e espanhol e estudos realizados em humanos.

Na primeira análise, após a leitura do título e resumo dos estudos primários $(\mathrm{n}=389)$, os artigos que não indicavam os aspectos emocionais das pacientes e a assistência prestada foram excluídos. Dentre eles: artigos que não atendiam a pergunta de pesquisa, e temas não relacionados. Na segunda análise, por meio da leitura do artigo na íntegra (n=10), excluiu-se um artigo excedente devido ao nível de evidência.

Após a coleta de dados, foi feita a leitura de todo material e as principais informações foram compiladas. Posteriormente foi realizada uma análise descritiva das mesmas, buscando estabelecer uma compreensão e ampliar o conhecimento sobre o tema pesquisado e elaborar o referencial teórico. 


\section{Resultados}

Os dez estudos incluídos nesta revisão estavam em igualdade nas línguas portuguesa (50\%) e inglesa (50\%). A maior parte das publicações foram concentradas no ano de 2016 (40\%) com abordagem qualitativa (80\%); O nível de evidência predominante foi alto, composto por estudos coorte (60\%) e revisões sistemáticas (40\%); O Brasil foi o país com mais estudos incluídos (60\%) (Tabela 1).

Tabela 1. Análise descritiva das produções científicas.

\begin{tabular}{lcc}
\hline VARIÁVEIS & N & $\%$ \\
\hline Abordagem do estudo & 08 & 80,0 \\
Qualitativo & 01 & 10,0 \\
Quantitativo & 01 & 10,0 \\
Qualitativo + quantitativo & & 60,0 \\
Delineamento da pesquisa & 06 & 40,0 \\
Estudo de coorte & 04 & 50,0 \\
Revisão sistemática & & 40,0 \\
Idioma & 05 & \\
Inglês & 05 & 30,0 \\
Português & & 70,0 \\
Classificação da evidência & 04 & 10,0 \\
Um & 06 & 60,0 \\
Três & & 10,0 \\
Procedência & 01 & 10,0 \\
Austrália & 06 & 10,0 \\
Brasil & 01 & 30,0 \\
Dinamarca & 01 & 40,0 \\
Irlanda & 01 & 10,0 \\
Quenia & & 10,0 \\
Distribuição temporal & 03 & 10,0 \\
2015 & 04 & 01 \\
2016 & 01 & \\
2017 & 01 & \\
2018 & & \\
2019 & &
\end{tabular}

Legenda: \% = percentual; $\mathrm{N}=$ número.

Fonte: Artigos pesquisados (2020).

Com relação a base dado, os autores, título do trabalho, objetivo principal e perfil amostral dos estudos analisados, podem ser observados no Quadro 3. Em geral, os artigos apresentaram a perspectiva da mulher após o abortamento e como isso afetou suas vidas no dia a dia e na possibilidade de uma futura gravidez. Eles avaliaram desde o processo da tomada da decisão e seus motivos, até meses depois, quando o pensamento da realização do ato ainda perdura. 
Quadro 3. Caracterização por base, autor, ano, título do trabalho, objetivo principal e perfil amostral. Caxias, MA, Brasil (2020).

\begin{tabular}{|c|c|c|c|c|}
\hline $\begin{array}{c}\text { Base de } \\
\text { dados }\end{array}$ & Autor/Ano & Título do Trabalho & Objetivo Principal & Perfil Amostral \\
\hline SCIELO & $\begin{array}{l}\text { Lemos e Cunha } \\
\quad(2015)\end{array}$ & $\begin{array}{l}\text { Concepções Sobre Morte e Luto: Experiência } \\
\text { Feminina Sobre a Perda Gestacional. }\end{array}$ & $\begin{array}{l}\text { Estudar como mulheres vivenciam e enfrentam a situação de } \\
\text { perda gestacional, com base na investigação dos aspectos } \\
\text { cognitivos (percepções e significados) e emocionais } \\
\text { (sentimentos) relacionados. }\end{array}$ & $\begin{array}{l}\text { Participaram } 11 \text { mulheres internadas no } \\
\text { alojamento conjunto de uma maternidade } \\
\text { pública no Rio de Janeiro. }\end{array}$ \\
\hline SCIELO & Sell et al. (2015) & $\begin{array}{l}\text { Motivos e significados atribuídos pelas mulheres } \\
\text { que vivenciaram o aborto induzido: revisão } \\
\text { integrativa. }\end{array}$ & $\begin{array}{l}\text { Identificar a contribuição de pesquisas desenvolvidas sobre o que } \\
\text { motiva as mulheres a induzir um aborto e o significado atribuído } \\
\text { a essas experiências em suas vidas. }\end{array}$ & $\begin{array}{l}11 \text { artigos das bases de dados } \\
\text { pesquisadas BDENF, LILACS, SCIELO, } \\
\text { CINAHL e MEDLINE. }\end{array}$ \\
\hline SCIELO & $\begin{array}{c}\text { Adesse, Jannotti, } \\
\text { Silva e Fonseca et al. } \\
\text { (2016) }\end{array}$ & $\begin{array}{l}\text { Aborto e estigma: uma análise da produção } \\
\text { científica sobre a temática. }\end{array}$ & $\begin{array}{l}\text { Objetiva analisar a produção científica sobre aborto e estigma } \\
\text { social e o potencial da categoria estigma para estudos sobre a } \\
\text { assistência ao abortamento no Brasil. }\end{array}$ & $\begin{array}{l}65 \text { publicações com as representações } \\
\text { sociais de mulheres que abortam e de } \\
\text { profissionais que as atendem. }\end{array}$ \\
\hline SCIELO & $\begin{array}{l}\text { McCallum et al. } \\
\text { (2016) }\end{array}$ & $\begin{array}{l}\text { O dilema de uma prática: experiências de aborto } \\
\text { em uma maternidade pública de Salvador, Bahia. }\end{array}$ & $\begin{array}{l}\text { Demonstrar que os processos de simbolização que integram a } \\
\text { atenção hospitalar às mulheres afetam, de modo contundente, } \\
\text { suas experiências. }\end{array}$ & $\begin{array}{l}\text { Jovens de } 15 \text { a } 24 \text { anos no Hospital } \\
\text { Maternal da Bahia. }\end{array}$ \\
\hline PUBMED & $\begin{array}{l}\text { Meaney, Corcoran, } \\
\text { Spillane e } \\
\text { O'Donoghue (2017) }\end{array}$ & $\begin{array}{l}\text { Experience of miscarriage: an interpretative } \\
\text { phenomenological analysis }\end{array}$ & $\begin{array}{l}\text { O objetivo do estudo foi explorar as experiências daqueles que } \\
\text { sofreram aborto espontâneo, concentrando-se nos relatos de } \\
\text { aborto de homens e mulheres. }\end{array}$ & $\begin{array}{l}\text { Uma amostra intencional de } 16 \\
\text { participantes, composta por } 10 \text { mulheres } \\
\text { e } 6 \text { homens, foi recrutada }\end{array}$ \\
\hline PUBMED & $\begin{array}{l}\text { Pitilin, Banazeski, } \\
\text { Bedin e Gasparin } \\
\text { (2016) }\end{array}$ & $\begin{array}{l}\text { Nursing care in situations of induced /caused } \\
\text { abortion: an integrative literature review }\end{array}$ & $\begin{array}{l}\text { Identificar na literatura científica sobre a assistência de } \\
\text { enfermagem em situações de aborto induzido/provocado }\end{array}$ & $\begin{array}{l}13 \text { publicações condensadas nas bases de } \\
\text { dados MEDLINE, SCIELO, BDENF e } \\
\text { LILACS }\end{array}$ \\
\hline BIREME & Santos e Brito (2016) & $\begin{array}{l}\text { Sentimentos de mulheres diante da concretização } \\
\text { do aborto provocado. }\end{array}$ & $\begin{array}{l}\text { Analisar os sentimentos experienciados por mulheres no } \\
\text { processo de concretização da prática abortiva. }\end{array}$ & $\begin{array}{l}19 \text { mulheres em situação } \\
\text { abortamento, internadas em uma } \\
\text { maternidade pública, localizada em } \\
\text { Natal, Rio Grande do Norte, Brasil. }\end{array}$ \\
\hline PUBMED & $\begin{array}{l}\text { Kofod e Brinkmann } \\
\text { (2017) }\end{array}$ & $\begin{array}{l}\text { Grief as a normative phenomenon: The diffuse } \\
\text { and ambivalent normativity of infant loss and } \\
\text { parental grieving in contemporary Western } \\
\text { culture }\end{array}$ & $\begin{array}{l}\text { Analisar como a perda de uma criança pequena em nossa cultura } \\
\text { é experimentada, interpretada e encenada dentro de uma estrutura } \\
\text { moral difusa e ambivalente, mas inescapável. }\end{array}$ & $\begin{array}{l}13 \text { casais enlutados após a perda do } \\
\text { bebê. }\end{array}$ \\
\hline PUBMED & $\begin{array}{l}\text { Bellhouse, Temple- } \\
\text { Smith e Bilardi } \\
\quad(2018)\end{array}$ & $\begin{array}{l}\text { It's just one of those things people don't seem to } \\
\text { talk about..." women's experiences of social } \\
\text { support following miscarriage: a qualitative } \\
\text { study. }\end{array}$ & $\begin{array}{l}\text { Explorar as experiências de apoio social das mulheres após o } \\
\text { aborto, com o objetivo de conscientizar a comunidade em geral } \\
\text { sobre as necessidades de apoio emocional das mulheres após o } \\
\text { aborto }\end{array}$ & $\begin{array}{l}\text { Mulheres entre } 18 \text { e } 50 \text { anos que tiveram } \\
\text { pelo menos um abortamento. }\end{array}$ \\
\hline PUBMED & $\begin{array}{l}\text { Mutiso, Murage e } \\
\text { Mwaniki (2019) }\end{array}$ & $\begin{array}{l}\text { Factors associated with a positive depression } \\
\text { screen after a miscarriage. }\end{array}$ & $\begin{array}{l}\text { Determinar os fatores associados a uma tela de depressão } \\
\text { positiva entre mulheres pós-aborto no hospital da Universidade } \\
\text { Aga Khan, Nairobi }\end{array}$ & $\begin{array}{l}\text { Mulheres que passar por aborto na } \\
\text { Clínica de Ginecologia de Nairobi. }\end{array}$ \\
\hline
\end{tabular}

Fonte: Estudos analisados (2020). 
Research, Society and Development, v. 10, n. 6, e33010615673, 2021

(CC BY 4.0) | ISSN 2525-3409 | DOI: http://dx.doi.org/10.33448/rsd-v10i6.15673

Os aspectos relacionados à idade das mulheres incluídas nas pesquisas dos autores analisados, além de seus respectivos graus de escolaridade e a presença de parceiros variam de acordo com a abordagem dos autores. Dentre os 10 autores analisados, apenas cinco destacaram a idade dessas mulheres, três pontuaram o nível de escolaridade e três relataram a presença de parceiros. A idade mais frequente observada, de acordo com as pesquisas, compreende o período entre os 20 e 40 anos e os aspectos relativos à existência ou não de escolaridade e parceiros variam significativamente de pesquisa para pesquisa,

As consequências emocionais decorrentes do processo de abortamento variam de acordo com as singularidades das mulheres que enfrentam o problema, não sendo possível, portanto, delinear de maneira homogênea estes reflexos, entretanto, de acordo com artigos analisados, boa parte das mulheres revelam algumas consequências em comum, das quais as mais frequentes são a culpa, luto, o medo e a ansiedade.

A identificação desses fatores nas pacientes que passam pelo processo de aborto exige uma preparação da equipe que lhes prestará assistência que, por sua vez, deve ser composta por especialidades multidisciplinares, objetivando o atendimento efetivo. Deste modo, foram identificados nos 10 artigos analisados a presença de proposição de características da assistência para essas mulheres, as quais sintetizou-se no Quadro 4 a seguir:

Quadro 4. Caracterização da assistência.

\begin{tabular}{|c|l|}
\hline AUTOR (S) & \multicolumn{1}{c|}{ CARACTERÍSTICAS DA ASSISTENCIA } \\
\hline $\begin{array}{c}\text { Adesse et al. } \\
(2016)\end{array}$ & $\begin{array}{l}\text { Os profissionais sofrem e propagam o estigma social do aborto e acabam por marginalizar a mulher, } \\
\text { evitando prestar tal tipo de assistência (que se tornou uma subespecialidade) }\end{array}$ \\
\hline $\begin{array}{c}\text { Lemos e Cunha } \\
(2015)\end{array}$ & $\begin{array}{l}\text { Há a necessidade da equipe de saúde estar sensível às demandas físicas, emocionais e sociais das } \\
\text { pacientes, proporcionando, assim, uma assistência integral e de qualidade. }\end{array}$ \\
\hline $\begin{array}{c}\text { Kofod e } \\
\text { Brinkmann } \\
(2017)\end{array}$ & $\begin{array}{l}\text { Profissionais de saúde diferentes instituições definem diferentes modos mais aceitos de se passar pelo } \\
\text { luto. }\end{array}$ \\
\hline $\begin{array}{c}\text { McCallum et al. } \\
(2016)\end{array}$ & $\begin{array}{l}\text { Prevalência de assistência técnica, com base nas necessidades físicas apresentadas pelas mulheres, } \\
\text { seguidas de assistência discriminatória, julgadora e burocrática. }\end{array}$ \\
\hline $\begin{array}{c}\text { Meaney et al. } \\
(2017)\end{array}$ & $\begin{array}{l}\text { Apesar das mulheres neste estudo não reclamarem dos profissionais, o espaço físico foi de grande } \\
\text { importância no estresse da assistência ao colocarem-nas junto com outras gestantes. }\end{array}$ \\
\hline $\begin{array}{c}\text { Pitilin et al. (2016) } \\
\text { Prevalência de assistência técnica, com base nas necessidades físicas apresentadas pelas mulheres, } \\
\text { seguidas de assistência discriminatória, julgadora e burocrática. }\end{array}$ \\
\hline $\begin{array}{c}\text { Santos e Brito } \\
\text { (2016) }\end{array}$ & $\begin{array}{l}\text { As pacientes revelam o medo de procurar assistência médica por medo dos julgamentos que } \\
\text { enfrentarão. Deve-se buscar uma atenção pós-aborto humanizada, ética, pautada na integralidade e } \\
\text { respeito à pessoa humana, percebe-se a existência de barreiras para os profissionais de saúde } \\
\text { incorporarem estes princípios e implementarem uma prática assistencial mais acolhedora. }\end{array}$ \\
\hline $\begin{array}{c}\text { Sell et al. (2015) } \\
\text { A negação do cuidado e da atenção dispensada pelos profissionais, por não estarem preparados para } \\
\text { não saber lidar com suas próprias crenças e valores, pode desencadear uma série de sentimentos que } \\
\text { refletirão sobre o significado que a mulher dará a essa experiência, principalmente quando houver } \\
\text { hospitalização, considerado desconfortável. }\end{array}$ \\
\hline
\end{tabular}

Fonte: Artigos pesquisados (2020).

Embora se compreenda a necessidade de atuação de uma equipe multidisciplinar dentro deste processo, após a realização da avaliação há que se ponderar sobre as melhores formas de abordagem, sendo o fluxograma abaixo, a representação esquematizada desses mecanismos, sob o viés da orientação educacional da paciente para com as formas de cuidado de si, e desta mesma abordagem em direção à equipe que a atenderá a necessidade de estruturação de espaço físico e de organização de equipe (Figura 1). 
Research, Society and Development, v. 10, n. 6, e33010615673, 2021

(CC BY 4.0) | ISSN 2525-3409 | DOI: http://dx.doi.org/10.33448/rsd-v10i6.15673

Figura 1. Fluxograma protocolo de atendimento às mulheres em processo de aborto.

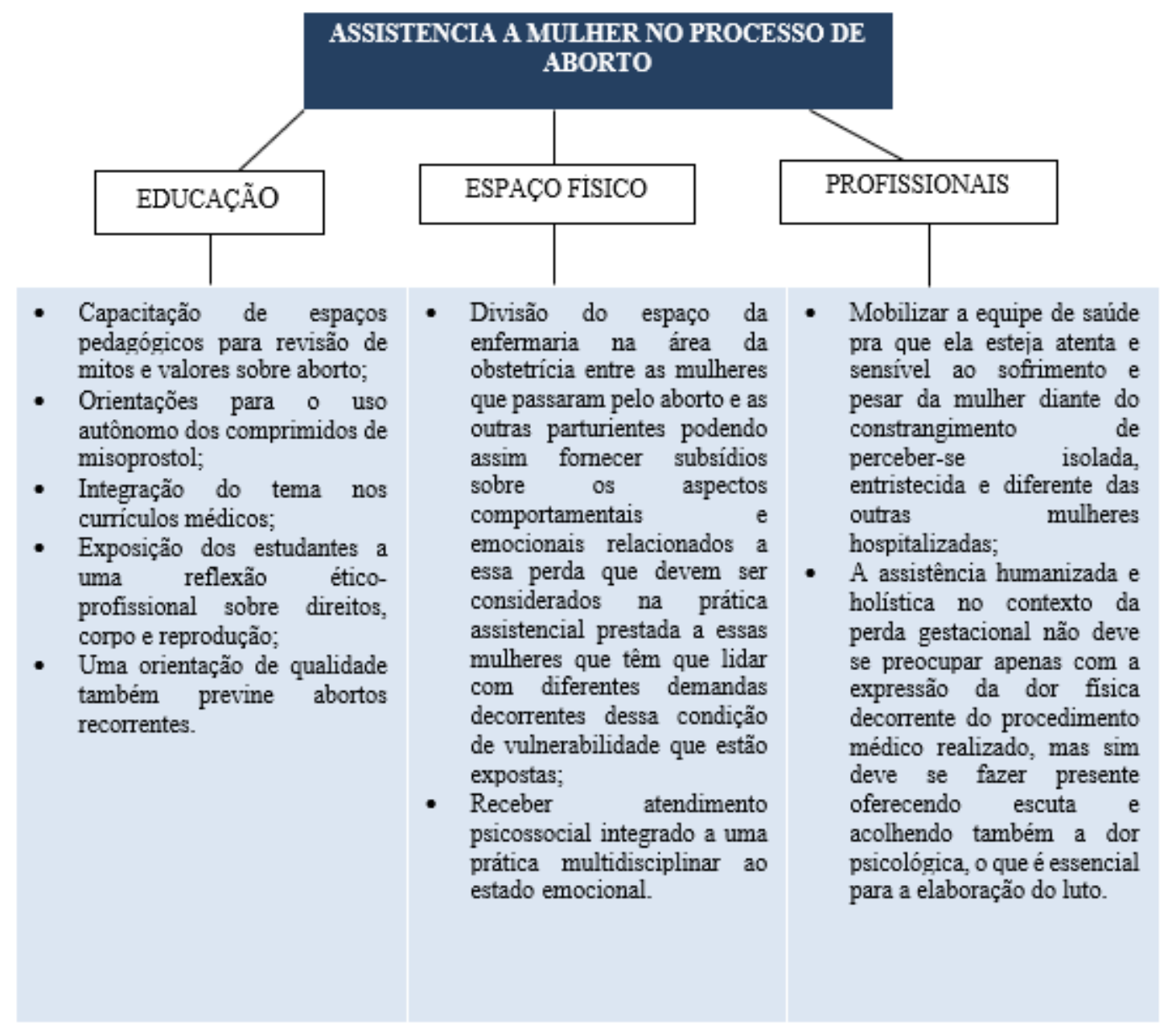

Fonte: Estudos analisados (2020).

\section{Discussão}

\section{Consequências emocionais decorrentes do abortamento}

No estudo de Sell et al. (2015), foi possível observar que os sentimentos que mais se destacaram pelas mulheres que sofreram aborto foram sentimento de culpa, medo de morrer, medo de castigo de Deus, pesar, remorso, arrependimento, dor fisiológica e existencial, medo de ser culpabilizada por outras pessoas e vergonha. Foram citados, ainda, outros sentimentos, porém em menor proporção e menos preocupantes, como sensação de abandono, tensão, perda da fé, baixa autoestima, hostilidade, raiva, desespero, desamparo, mágoa, desejo de romper o relacionamento com o parceiro, perda de interesse sexual e sentimentos ruins relacionados às pessoas ligadas à situação.

Diante disso, pode-se perceber que o processo de abortamento é um ponto de partida para vários problemas, indo desde os emocionais, em decorrência da situação, até o preconceito e julgamento por parte de alguns profissionais, o que dificulta ainda mais a vivência desse momento.

Corroborando com essa afirmação, McCallum et al. (2016) destacam a experiência de mulheres durante o abortamento, na qual as pacientes citaram como bastante negativa durante o período de internação na maternidade. As mesmas relataram preconceito por parte dos profissionais, falta de humanização no cuidado, e o sentimento de vergonha por considerar que por se tratar de aborto não podiam reclamar. 
Research, Society and Development, v. 10, n. 6, e33010615673, 2021

(CC BY 4.0) | ISSN 2525-3409 | DOI: http://dx.doi.org/10.33448/rsd-v10i6.15673

No estudo realizado por Lemos e Cunha (2015) evidenciou-se que além de lidar com o trauma da realização do procedimento de curetagem no aborto, as mulheres ainda enfrentavam outras reações emocionais em consequência da perda do filho que esperava, como aperto no peito (angústia); medos ligados à possibilidade de vivenciar uma nova gestação pós-perda; tristeza; sensação de vazio; desmotivação; decepção; culpa; frustração; fracasso; impotência e constrangimento, demonstrando, assim, o quanto o abortamento pode ser traumático em vários aspectos.

Levando em consideração todos esses sentimentos próprios em decorrência do processo do aborto que a mulher tem que vivenciar, ainda há a questão dos aspectos referentes à moralidade e à religião, onde muitas delas transcorrem pela ideia de que o abortamento é um ato merecedor de castigo devido à ideologias já enraizadas no ambiente social em que vivem, tendo como regras sociais a obrigatoriedade de serem punidas. Dessa forma, elas vivenciam o medo quanto à intensidade da punição a ser aplicada sobre elas por uma entidade divina, sendo o medo da morte, o do nascimento de um filho com deficiência ou a impossibilidade de gerar outros filhos no futuro os mais citados (Santos \& Brito, 2016).

Com relação a isso, Adesse et al. (2016), o estudo traz que esse estigma em decorrência do abortamento, envergonha e faz calar quem decide interromper uma gravidez, assim como os profissionais que participam da assistência, pois a mulher acaba acreditando que a revelação do aborto pode criar conflitos e isso leva a influenciar a decisão da mulher sobre contá-lo ou não ao parceiro, à família, a amigos e até mesmo a profissionais de saúde sobre o acontecido. Esse emaranhado de sentimentos e emoções faz com que ela se estigmatize pelos acontecidos, mesmo quando o aborto acontece de forma espontânea.

O preconceito já enraizado sobre o aborto na sociedade atual, acaba por fazer com que isso se torne um problema ainda maior, pois o medo de revelar suas intenções ou revelar o ocorrido gera um conflito de emoções na mulher, em que passar pelo trauma do aborto e suas consequências, leva ela a ter um anseio de dúvidas e medos, que poderiam ser resolvidos com os cuidados adequados e humanizados.

\section{O processo do luto no abortamento}

O luto após um aborto é um estágio extremamente difícil, porém necessário. Muitas vezes visto como um tabu, é fundamental que ele seja vivenciado de forma efetiva, para que não venha a se tornar um luto patológico (Lemos \& Cunha, 2015). Relacionado à isso, o estudo realizado por Kofod e Brinkmann (2017), com 13 pais enlutados após a ocorrência de aborto, demonstrou que há uma ambivalência normativa no processamento do luto, no qual os pais precisam achar um equilíbrio entre lamentar "muito" ou lamentar "muito pouco", pois muitas vezes o luto "muito pouco" é interpretado ou está relacionado a um enfrentamento psicológico insatisfatório, como a repressão ou negação.

Por vezes, amigos e familiares não entendem a importância do luto, todavia, é fundamental que as pessoas do convívio social desses pais, principalmente da mulher, tenham consciência e respeitem o tempo do luto sem considerar as emoções despertadas por ele algo que remete a frieza ou algo exagerado, devendo buscar sempre oferecer suporte e apoio a quem vivencia essa situação.

A maioria dos estudos evidenciou que as mulheres após sofrerem aborto, seja ele espontâneo ou provocado, preferem não falar sobre a perda, reação essa característica da fase de negação do luto. Tal fato é retratado na pesquisa de Lemos e Cunha (2015), realizada no Rio de Janeiro com 11 mulheres internadas em uma maternidade em decorrência de aborto, na qual, no geral, as entrevistadas relataram que procuram não manifestar seu sofrimento pela perda, evitando falar, lembrar ou escutar sobre o assunto como uma forma de minimizar a dor. Em contrapartida, o estudo de Bellhouse et al. (2018), feito na Austrália com 15 mulheres vítimas de aborto, retratou que as participantes preferiam falar sobre o assunto, expondo seus sentimentos e reconhecendo a perda, pois para elas não reconhecer era como se não importassem.

É sabido que a escolha de não falar sobre a perda ocorrida funciona como um mecanismo de defesa, que é algo 
Research, Society and Development, v. 10, n. 6, e33010615673, 2021

(CC BY 4.0) | ISSN 2525-3409 | DOI: http://dx.doi.org/10.33448/rsd-v10i6.15673

necessário para enfrentar situações de luto, entretanto, essa escolha pode acarretar em um maior sofrimento psíquico, trazendo resultados insatisfatórios e consequências no futuro.

Um ponto relevante apontado no estudo de Lemos e Cunha (2015), é que mulheres que já vivenciaram uma ou mais perdas consecutivas, passam por um processo de luto mais difícil e delicado. Corrobora com essa afirmativa, o estudo de Mutiso et al. (2019) realizado com 182 mulheres, que demonstrou que a presença de aborto prévio aumenta em 43,2\% a chance de ocorrência de depressão e, consequentemente, a vivência de um luto precário.

Outro fator que determina a intensidade ou qualidade do luto é o avanço da idade materna, pois quanto maior, mais os pais constroem no seu íntimo o papel parental. Verificou-se que a idade gestacional avançada no aborto apresenta maiores chances de ocorrência de depressão e aumento da duração do luto vivenciado (Meaney et al., 2016; de Mutiso et al. 2019).

A dor do luto é algo incomparável, que se diferencia de pessoa para pessoa, porém a intensidade dessa dor vivenciada nesse momento dependerá do vínculo afetivo criado, quanto maior o tempo de gravidez maior será o vínculo construído entre a mãe e o bebê, maiores serão os planos e maiores serão as expectativas idealizadas.

É fundamental considerar também que a mulher que sofre aborto pode apresentar comportamentos agressivos com a equipe de saúde, familiares ou amigos, característica comum durante a fase de raiva. Segundo Lemos e Cunha (2015), o apoio, acolhimento e suporte tanto da equipe de saúde, como de familiares e amigos, colaboram na experiência simbólico do luto.

\section{Assistência de enfermagem no abortamento}

No estudo de Kofod e Brinkmann (2017), pais que participaram da pesquisa relataram que receberam apoio e simpatia dos profissionais por sua perda após o aborto, mas também foram referidas situações em que a perda do feto foi atendida com comentários que eles sentiram como inadequados ou ofensivo, como "foi bom que aconteceu agora e não mais tarde", implicando que a perda é de alguma forma substituível e, portanto, menos grave do que se a criança fosse mais velha.

Por meio da análise das pesquisas, é perceptível que há uma diferença sobre como a equipe de enfermagem se comporta frente a um aborto provocado e sobre como ela se comporta frente a um aborto espontâneo. O estudo de McCallum et al. (2016) realizado com 19 profissionais, entre eles 5 enfermeiros e 6 técnicos de enfermagem, retratam que as mulheres que sofreram aborto espontâneo são discriminadas e maltratadas por serem confundidas com mulheres que provocaram o aborto, tendo que muitas vezes convencer os profissionais que não causaram a interrupção da gravidez.

É extremamente necessário que haja um atendimento mais adequado a essas mulheres. O profissional deve ter consciência que sua maior responsabilidade é prover cuidados de qualidade baseados em evidências e sistematizados, abondando suas crenças e valores particulares, a fim de prestar uma assistência livre de preconceitos ou julgamentos de valor, independentemente da situação ou circunstância.

Ações realizadas pelos hospitais para informar os profissionais sobre um atendimento mais humanizado nestas situações são de fundamental importância, pois são elas que fazem os profissionais refletirem em suas atitudes e buscarem modificá-las (Adesse et al., 2016).

No que tange a isso, McCallum et al. (2016) destacam, ainda, que o profissional de saúde deve estar ciente de que seus atos para com a mulher que necessita de assistência podem refletir no seu futuro, e se estes tiverem reflexo de uma conduta inadequada, prejudicarão de uma maneira imensurável a saúde psicológica da paciente. Sendo assim, deve-se cuidar da cliente como um todo, usufruindo de suas competências, buscando o trabalho com uma equipe multiprofissional em que todos estejam em prol de uma total humanização e sigilo, se esse for o caso e o desejo da mulher.

A assistência do enfermeiro não deve se resumir apenas em ações e intervenções em saúde, mas, antes, deve constituir-se no desenvolvimento de atitudes genuínas, amparadas pela tecnologia, sem se deixar resumir a ela. Como são os 
Research, Society and Development, v. 10, n. 6, e33010615673, 2021

(CC BY 4.0) | ISSN 2525-3409 | DOI: http://dx.doi.org/10.33448/rsd-v10i6.15673

primeiros a terem contato com as pacientes, é importante que eles estejam devidamente sensibilizados sobre não somente seu estado físico como também seu estado mental (Lemos \& Cunha, 2015).

O estado mental já frágil dessas mulheres fica exposto constantemente a sua perda, a do seu bebê e de seu futuro. Deve-se estar atento diante do constrangimento de perceber-se isolada, entristecida e diferente das outras mulheres hospitalizadas. Relevante também considerar que esta mulher durante a internação, em função do seu estado de humor, pode ter atitudes agressivas com a equipe. Diante disso, geralmente, a primeira atitude do profissional é achar que ela não está colaborando com o tratamento e rejeitando sua assistência, quando, na verdade, tal reação nada mais é do que uma demonstração da dor e dificuldade vivenciada por ela naquele momento, necessitando assim, de uma assistência atenciosa (Kofod \& Brinkmann, 2017).

O estigma relacionado ao aborto não afeta apenas a mulher, mas também os profissionais de saúde, cujas práticas muitas vezes deixam claro sua posição sobre o assunto. Seu posicionamento acarreta uma assistência não humanizada, discriminatória e técnica, que gera ainda mais uma dificuldade por parte das pacientes em procurar os serviços de saúde (Adesse et al., 2016; Kofod \& Brinkmann, 2017; Lemos \& Cunha, 2015; McCallum et al. 2016; de Mutiso et al., 2019; Pitilin et al., 2016; Santos \& Brito, 2016; Sell et al., 2015)

Com relação a atuação dos profissionais frente essa situação McCallum et al. (2016), citam a percepção de alguns profissionais, no qual eles relatam que há uma relação complexa entre as percepções dos profissionais acerca do aborto em adolescentes e as atitudes que assumem diante das pacientes. Uma opinião contrária ao aborto não leva necessariamente a uma condenação moral incondicional da paciente nem a uma atitude discriminatória em relação a ela, entretanto, essa visão pessoal da situação acaba por levar o profissional a ter reações diferentes com elas. Eles entendem que as adolescentes acabam por abortar de modo indiscriminado, no entanto, alguns relataram que as jovens por falta de experiência e conhecimento engravidam, acreditando, assim, que a gravidez não deveria ser considerada sua exclusiva responsabilidade.

Dessa forma, a ação da equipe de saúde que presta assistência a essas mulheres deve ser neutra e imparcial, independentemente de suas convicções, pois só assim o cuidado será feito de forma integral e universal. Os estudos destacam o quanto a já estigmatizada situação interfere no cuidado a paciente e nas suas reações diante de um aborto provocado.

Em razão desse estigma, muitas mulheres preferem manter silêncio sobre o aborto e se isolam em luto. Esse silêncio causa um ciclo vicioso, pois como se torna um assunto pouco discutido, outras pacientes também não se sentem seguras em revelar suas ações, reforçando a ideia padronizada sobre o aborto como algo inusitado e inaceitável (Pitilin et al., 2016).

\section{Considerações Finais}

As mulheres no processo de aborto passam por um processo contínuo de desrespeito, são culpabilizadas e discriminadas, sofrendo diversos atos de violência de ordem física, emocional, moral, institucional e psicológica, perpetuando uma atenção desqualificada perante a um cuidado de qualidade.

Os dados apresentados nesta pesquisa têm o intuito de apresentar a natureza multifacetada do aborto descrito na literatura cujo impacto da perda, atinge diretamente a vida da mulher. Ele afeta sua autoestima, o modo como ela vê o próprio corpo, seu estado de espírito e uma possível futura gravidez. Deve-se salientar ainda, a importância da participação e apoio familiar e da sociedade em que está inserida, assim como dos profissionais de saúde que a acompanham desde o prognostico até durante a internação hospitalar.

A assistência a essas mulheres não deve ser mecanizada, ou seja, um cuidado voltado só para a parte técnica, pois ela está em uma situação de tensão psicológica e emocional. Neste momento é esperado exercer a competência profissional, além 
Research, Society and Development, v. 10, n. 6, e33010615673, 2021

(CC BY 4.0) | ISSN 2525-3409 | DOI: http://dx.doi.org/10.33448/rsd-v10i6.15673

de um conjunto de atividade para o trabalho multiprofissional, respeitando com uma escuta ativa e o seu acolhimento. Mulheres em situação de abortamento nos serviços de saúde, não apresentam apenas problemas físicos como sangramento e cólicas, mas também problemas psicológicos em razão da culpa, ansiedade e medo pelo fim da gestação. Esses problemas se intensificam ao enfrentar profissionais de saúde que não são capazes de fornecer um acolhimento humanizado.

Conclui-se que o presente estudo contribui para uma reflexão profunda sobre a saúde da mulher e a contribuição da enfermagem frente a mulher que passou pelo processo de aborto, podendo ser induzido ou espontâneo, assim como a assistência e condutas éticas prestadas pelos profissionais de enfermagem.

\section{Referências}

Adesse, L., Jannotti, C. B., Silva, K. S., \& Fonseca, V. M. (2016). Aborto e estigma: uma análise da produção científica sobre a temática. Ciência \& Saúde Coletiva, 21(12), 3819-3832.

Bellhouse, C., Temple-Smith, M. J., \& Bilardi, J. E. (2018). “É apenas uma daquelas coisas que as pessoas parecem não falar ...” Experiências de apoio social de mulheres após aborto espontâneo: um estudo qualitativo. BMC Women's Health, 18, e176.

Cardoso, B. B., Vieira, F. M. S. B., \& Saraceni, V. (2020). Aborto no Brasil: o que dizem os dados oficiais? Cadernos de Saúde Pública, 36(Suppl. 1), e00188718.

Kofod, E. H., \& Brinkmann, S. (2017). Luto como fenômeno normativo: a normatividade difusa e ambivalente da perda infantil e do luto dos pais na cultura ocidental contemporânea. Culture \& Psychology, 23 (4), 519-533.

Lemos, L. F. S., \& Cunha, A. C. B. da. (2015). Concepções Sobre Morte e Luto: Experiência Feminina Sobre a Perda Gestacional. Psicologia: Ciência e Profissão, 35(4), 1120-1138.

McCallum, C., Menezes, G., \& Reis, A. P. dos. (2016). O dilema de uma prática: experiências de aborto em uma maternidade pública de Salvador, Bahia. História, Ciências, Saúde-Manguinhos, 23(1), 37-56.

Meaney, S., Corcoran, P., Spillane, N., \& O'Donoghue, K. (2017). Experiência de aborto espontâneo: uma análise fenomenológica interpretativa. BMJ Open, 7(3), e011382.

Mirabete, J. F., \& Fabrinni, R. N. (2018). Manual de Direito Penal. (34 a ed.): Atlas.

Mutiso, S. K., Murage, A., \& Mwaniki, A. M. (2019). Fatores associados a uma tela de depressão positiva após um aborto espontâneo. BMC Psychiatry, 19 (8), $1-6$.

Nonnenmacher, D., Benute, G. R. G., Nomura, R. M. Y., Azevedo, G. D., Dutra, E. M. S., Rebouças, M. S. S., Luci, M. C. S., \& Francisco, R. P. V. (2014). Abortion: a review of women's perception in relation to their partner's reactions in two Brazilians cities. Revista da Associação Médica Brasileira, 60(4), 327334.

Oliveira, F. B. M., Costa, C. A. L., Alves, D. L., França, J. F. D., Macedo, M. S. D., \& Santos, R. D. D. (2016). Relação entre a sobrecarga de trabalho e erros de administração de medicação na assistência hospitalar. Revista Ciências \& Saberes, 2(2).

Oliveira, L. A. C., \& Rodrigues, T. C. F. (2014). A descriminalização parcial do aborto. Athenas, 1(3), 13-27.

Pitilin, E. B., Banazeski, A. C., Bedin, R., \& Gasparin, V. A. (2016). Nursing care in situations of induced /caused abortion: an integrative literature review. Enfermeria Global, 15(43), 439-451.

Roldán, M. (2016). Factores psicosociales asociados en mujeres con aborto. Hospital Roosevelt, Guatemala, septiembre 2015. Rev. Col. Méd. Cir. Guatem., $155(1), 28-32$.

Santos, D. L. A., \& Brito, R. S. (2016). Sentimentos de mulheres diante da concretização do aborto provocado. Revista Enfermagem UERJ, 24(5), e15613

Sell, S. E., Santos, E. K. A., Velho, M. B., Erdmann, A. L., \& Rodriguez, M. J. H. (2015). Motivos e significados atribuídos por mulheres que vivenciaram o aborto provocado: uma revisão integrativa. Revista Da Escola de Enfermagem da USP, 49 (3), $495-501$. 